\title{
Design of On-board Weighing System Based on STM32
}

\author{
Yu Zhang*, Qiang Zhao, Xuemeng Liang, Huanbo Qiao
}

\author{
School of Transportation and Vehicle Engineering \\ Shandong University of Technology, Zibo 255000, China \\ *corresponding author: Dr. Yu Zhang; zhangyu7819@163.com
}

\begin{abstract}
In order to solve the problem of overloading, an on-board weighing system based on STM32 is designed. The on-board weighing system is directly installed on the vehicle, and the on-board weight is measured by collecting the strain produced by the loading of the truck frame. This paper describes the research background and significance of the on-board weighing system, focusing on the structure of the semi-trailer on-board weighing system, system workflow and the realization of each part.
\end{abstract}

Keywords: on-board weighing system; Cargo vehicles; Strain sensor; STM32

\section{INTRODUCTION}

With the prosperity of the national economy and the improvement of the highway network, the transportation industry ushered in rapid development, a variety of trucks have been widely used in many industries [1-3]. But in order to reduce the transportation cost of goods, some vehicle drivers often overload the goods.[4] Vehicle overload transportation will cause great harm to the vehicle itself, society, pedestrians, the environment, etc. [5-6]. The traffic management department has taken a series of measures, put a lot of manpower and material resources to control the problem of vehicle overload, although some achievements have been made, reduce the phenomenon of overload, but not completely put an end to the problem of overload [7-8].

Therefore, in view of the above problems, this paper designs an on-board weighing system applied to the truck. This paper mainly introduces the structure, work flow and the concrete realization of each part of the load on-board weighing system.

\section{SYSTEM INTRODUCTION}

The on-board weighing system is a weighing instrument directly installed on the truck. The on-board weighing system designed in this paper consists of data acquisition part, data processing part, human-computer interaction part and power supply part. The data acquisition part is composed of a strain sensor module and conversion module, and the human-computer interaction part is composed of a display module and alarm module. The schematic diagram of system structure is shown in FIGURE 1.

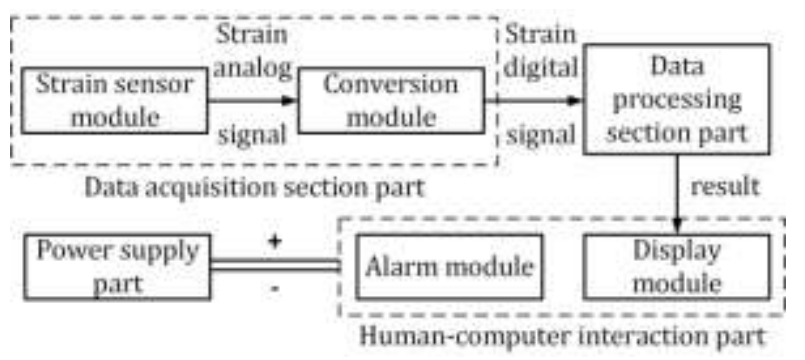

FIGURE 1: Schematic diagram of structural composition of on-board weighing system
The work flow of an on-board weighing system is as follows: the strain sensor module in the data acquisition part collects the strain analog signal generated by the frame of the carrying vehicle after it bears the load, and the conversion module converts the strain analog signal into the strain digital signal and sends it to the data processing part; the data processing part calculates and processes the above data to get the load value of the vehicle, and then controls the human-computer interaction part to achieve the corresponding functions; the power supply is obtained from the semi-trailer battery to provide stable voltage for the entire on-board weighing system.

\section{OVERALL DESIGN OF ON-BOARD WEIGHING SYSTEM Design of Data Acquisition Part}

- Design of Strain Sensor Module

Four single bridge strain gages were assembled into full bridge strain gages by using the connection mode of Wheatstone bridge. The full bridge strain gauge can be used as the strain sensor module of the cargo vehicle to measure the deformation of the vehicle after bearing the load. The single-bridge strain gauge is shown in FIGURE 2, and the connection mode of Wheatstone bridge is shown in FIGURE 3.

The strain gauge is made of semiconductor material based on strain effect. When the strain gauge is deformed, the cross-sectional area of the metal material inside the strain gauge will change, leading to the change of its resistance, and thus the voltage on both sides of the strain gauge will change.

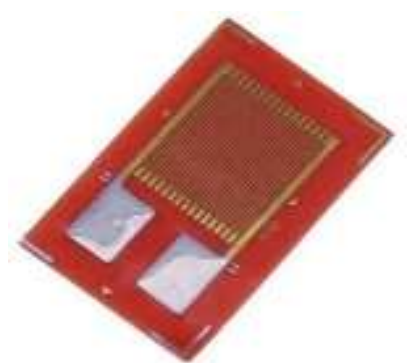

FIGURE 2: Single bridge strain gauge 


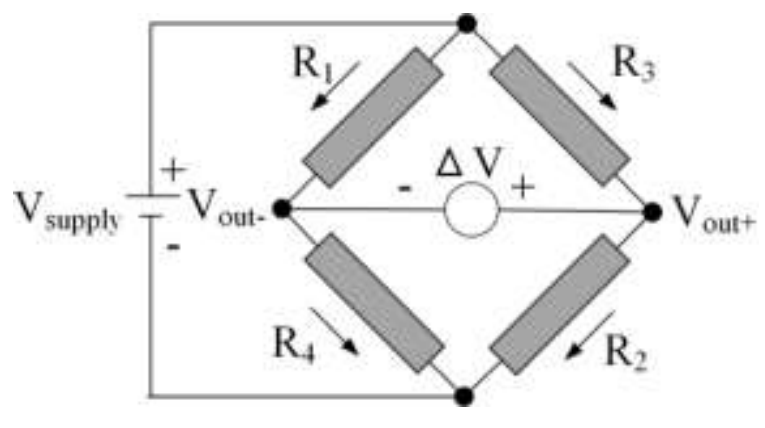

FIGURE 3: Wheatstone bridge

The sensor module is installed at the bottom of the frame rail of the truck, and the strain gauge will produce the corresponding resistance change with the deformation of the frame. After the semi-trailer frame is loaded with goods, the frame is deformed, and the resistance of the strain gauge changes, which causes the voltage change. By collecting the voltage value of the strain gauge, the deformation signal of the frame can be converted into the voltage signal that can be used for calculation.

\section{- Design of Transmission Module}

The output signal of the strain gauge in the sensor module is analog signal and its value is very small, so it can only be used after amplification processing by the amplifier circuit in the transmission module. The conversion module of the on-board weighing system of the cargo vehicle adopts HX711 AD conversion chip, which is a special module for 24bit weighing measurement digital-to-analog conversion, which is used to receive the voltage analog signal transmitted by the sensor module, and amplify and convert it. After the voltage analog signal is processed by the conversion module, it becomes the voltage digital signal. In order to ensure the measurement accuracy and antiinterference ability, each strain sensor is connected with an AD conversion chip. PCB board of AD conversion module is shown in FIGURE 4

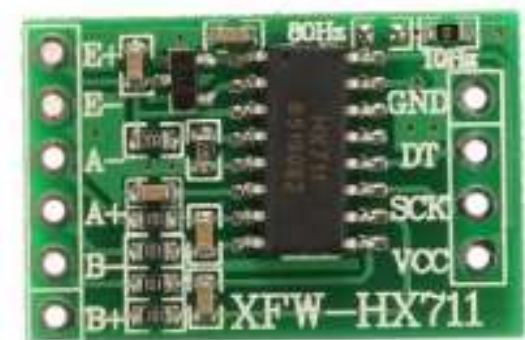

FIGURE 4: PCB board of AD conversion module

\section{Design of Data Processing Part}

The data processing part is the key of the on-board weighing system, which processes the received data to get the vehicle weight value, and then controls the humancomputer interaction part to realize the corresponding functions. The weighing system selects STM32F103 as the terminal processing MCU, through the analysis and calculation of the data measured in the data acquisition part, the vehicle load can be obtained, and then judge whether the vehicle is overloaded or unbalanced.

STM32F103 belongs to the low-end 32-bit ARM microcontroller, as shown in FIGURE 5. It adopts the core of Cortex-M3. The MCU integrates the advantages of high performance, high integration, low power consumption, low voltage and so on. Moreover, this series of MCU has rich external resources, which are convenient for later development and upgrading.

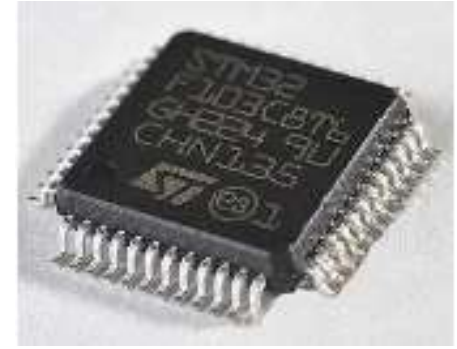

FIGURE 5: STM32F103 microcontroller

\section{Human-Computer Interaction Part}

The human-computer interaction part is installed in the cab of the semi-trailer and consists of a display module and an alarm module. The display module is used to display the weight value of the vehicle; alarm module is used to remind the driver when the vehicle is overloaded, partial load or goods fall off.

\section{Power Supply Part}

The power supply part takes power from the battery of the semi-trailer to provide a stable voltage for the whole system. This weighing system uses AMS1117's 5V voltage regulator chip to design a micro power supply module. After the voltage of $12 \mathrm{~V}$ is decompressed, it can provide stable $3.3 \mathrm{~V}$ and $5 \mathrm{~V}$ voltages for the whole system.

\section{SUMMARY}

on-board weighing system can obtain vehicle weight conveniently, and plays an important role in the treatment of vehicle overload. Based on STM32, this paper designs an on-board weighing system installed on the truck, introduces the structure of the on-board weighing system, the work flow, and focuses on the realization of the onboard weighing system parts.

\section{REFERENCE}

[1] G Radoičić, M Jovanović, M Arsić. Experience with an On-board Weighing System Solution for Heavy Vehicles[J]. Etri Journal, 2016, 38.

[2] Maraini D . Railway Freight car on-board weighing system[J]. 2015.

[3] Zhang R , Luo X , Chenguang X U , et al. On-board weighing monitor system based on Internet of things. Journal of Computer Applications, 2014.

[4] Devlin G . Assessing the accuracy of new innovative on board weighing devices for timber haulage. 2013.

[5] Lydon M, Taylor S E , D Robinson, et al. Development of a Bridge Weigh-in-Motion Sensor: Performance Comparison Using Fiber Optic and Electric Resistance Strain Sensor Systems[J]. IEEE Sensors Journal, 2014, 14(12).

[6] Yedire R, Shah A A. On-Board weighing system using ultrasonic transducers to measure effective payload on a truck. 2017.

[7] Keith, Loria. Trends in Onboard Scales: A look at the latest advancements in onboard weighing products[J]. Weigh \& Measure: Industrial Weigh \& Measure Handling Systems Magazine, 2015.

[8] Seku A K , Ko Akowski P . Piezo-based weigh-inmotion system for the railway transport[J]. Structural Control \& Health Monitoring, 2012, 19(2):199-215. 